\title{
LA REFORMA DEL PROCESO CANÓNICO PARA LA DECLARACIÓN DE NULIDAD DEL MATRIMONIO. ALGUNAS CONSIDERACIONES SOBRE SUS OBJETIVOS Y LAS NOVEDADES INTRODUCIDAS PARA ALCANZARLOS
}

\author{
THE REFORM OF THE CANONICAL PROCESS FOR THE \\ DECLARATION OF NULLITY OF MARRIAGE. SOME \\ CONSIDERATIONS ABOUT ITS OBJECTIVES AND THE MAJOR \\ CHANGES IN ORDER TO ACHIEVE THEM
}

\section{VALERIa López MANCINI ${ }^{1 *}$}

\begin{abstract}
RESUMEN: El Motu proprio Mitis Iudex Dominus Iesus, del Papa Francisco, introduce importantes modificaciones en los procesos para la declaración de nulidad del matrimonio. Este ensayo busca presentar algunos de los desafíos que propone la reforma, a través de las principales novedades introducidas, señalando, también, que este tiempo inicial de su implementación, constituye un ámbito propicio para que la doctrina presente los aciertos y desventajas de la reforma procesal.
\end{abstract}

Palabras clave: Proceso canónico, reforma del proceso de nulidad, potestad judicial, tribunales eclesiásticos.

ABSTRACT: The Motu proprio Mitis Iudex Dominus Iesus, by Pope Francis, introduces important modifications in the processes to declare the nullity of marriage. This essay analyzes some of the challenges that the reform proposes, through the main innovations introduced, especially regarding the objective pursued by the Legislator, noting, also, that in this first stage of its implementation, constitutes a propitious area for the doctrine to present the successes and disadvantages of procedural reform.

Key words: Canonical procedure, reform of the marriage annulment process, judicial power, ecclesiastical tribunal.

\section{INTRODUCCIÓN}

La reforma de los procesos canónicos para la declaración de nulidad del matrimonio, realizada por el Papa Francisco, fue presentada por la Santa Sede el 8 de septiembre de 2015, con la Carta Apostólica, en forma de motu proprio, Mitis Iudex Dominus Iesus (en adelante Motu proprio), para entrar en vigor el 8 de diciembre ${ }^{2}$. El texto fue presentado en

\footnotetext{
1 *Abogada, Licenciada en Derecho Canónico de la Universidad Católica Argentina, Profesora de la Facultad de Derecho de la Pontificia Universidad Católica de Chile. Patrona estable del Tribunal Interdiocesano de Santiago. Dirección postal: Catedral 1063, piso 7, Santiago; Dirección electrónica: vlopez@iglesia.cl.

2 Se promulgaron dos Cartas Apostólicas, una para la Iglesia latina, que es sobre la que trata este trabajo, Litterae Apostolicae Motu Proprio datae Mitis Iudex Dominus Iesus quibus canones Codicis Iuris Canonici de causis ad matrimonii nullitatem declarandam reformantur, y otra para las Iglesias orientales, Litterae Apostolicae Motu Pro-
} 
rueda de prensa y si bien la forma establecida para la promulgación es su publicación en el boletín oficial Acta Apostolicae Sedis ${ }^{3}$, debido al frecuente atraso en la aparición de dicho boletín, se considera promulgada, de hecho, a partir de su incorporación en el sitio web vaticano y en el Boletín n. 0652 de la Sala Stampa della Santa Sede, del mismo día 8 de septiembre de 2015.

Al haberse cumplido ya un año de vigencia de las nuevas normas, y aunque pudiera parecer prematuro hacer una reflexión sobre lo que ha sido la aplicación de las mismas y el efectivo cumplimiento de los objetivos planteados por el Legislador, este trabajo pretende presentar una mirada sobre los principales desafíos que ha presentado la reforma, y algunos interrogantes sobre las novedades introducidas por la misma, que la doctrina ha ido señalando. En efecto, desde la presentación de la reforma se han desarrollado numerosos seminarios, congresos y cursos, organizados por distintas universidades, asociaciones de derecho canónico, tribunales y conferencias episcopales ${ }^{4}$, que han originado la producción de mucho material bibliográfico, alguno ya publicado en las principales revistas especializadas 5 .

El escenario antes descrito se entiende porque, si bien se trata de una reforma meramente procesal -en el sentido de que el derecho matrimonial sustantivo no ha sido modificado- existía ya una gran expectación acerca de algunos cambios que se venían proponiendo hacía tiempo y que fueron abordados especialmente en el Sínodo de los Obispos del año $2014^{6}$. El Papa Francisco no solo presentó las nuevas normas, sino que fue enfático en la necesidad de su cumplimiento, tal como surge del Rescripto que dio a conocer poco después de presentada la reforma ${ }^{7}$; en iguales términos se pronunció el Decano del Tribunal la Rota Romana, Monseñor Pio Vito Pinto, en la nota explicativa del Rescripto, publicada

prio datae Mitis et Misericors Iesus quibus canones Codicis Canonum Ecclesiarum Orientalium de Causis ad Matrimonii nullitatem declarandam reformantur. Véase FranCISCO (2015 b) y FRANCISCO (2015 c).

3 Canon 8.

4 A modo de ejemplo y solo por señalar algunos: el VI Curso de Actualización en Derecho Matrimonial Canónico, Pontificia Universidad de la Santa Cruz, en Roma, 19 a 23 de septiembre de 2016, Roma; Seminario de Estudio Le littarae Motu proprio sulla riforma dei processi di nullità matrimoniale: una prima analisi Pontificia Universidad Lateranense, en Roma, 19 de octubre de 2015; XXVIII Curso de Actualización en Derecho Canónico de Familia, Universidad de Navarra, en Pamplona, 12 y 13 de noviembre de 2015; Jornada de estudio y debate sobre la nueva legislación, Universidad Pontificia Comillas, en Madrid, 18 de noviembre de 2015; Jornada de estudio de las nuevas normas organizada por la Asociación Chilena de Derecho Canónico y la Facultad de Derecho de la Pontificia Universidad Católica de Chile, en Santiago, 22 de octubre de 2015; las Jornadas de la Sociedad Argentina de Derecho Canónico, en Mar del Plata, 28 y 29 de octubre de 2015; las Jornadas anuales de la Asociación Chilena de Derecho Canónico, en Lo Vásquez, 11 a 15 de julio de 2016.

5 Podemos encontrar artículos relacionados con la reforma procesal, publicados en las principales revistas especializadas, ya desde fines de 2015 y en el año 2016, por ejemplo: Ius Ecclesiae vol. XXVIII n 1, Ius Canonicum vol. 56, Annali di dottrina e giurisprudenza canonica 16, Studi Giuridici 27, Estudios Eclesiásticos vol. 90, $\mathrm{n}^{\circ}$ 355, Anuario Argentino de Derecho Canónico vol. 21, Anuario Canónico de la Asociación Chilena de Derecho Canónico vol. II.

6 Sínodo de los obispos, III Asamblea General Extraordinaria (2014 a) El Instrumentum laboris en sus números 98 a 102, ya mencionaba distintas propuestas encaminadas a agilizar y simplificar los procesos, a la vez que hacerlos más accesibles a los fieles.

7 Francisco (2015 d). En efecto, el 11 de diciembre el Papa Francisco presentó el Rescripto pontificio sobre la reforma del proceso matrimonial, con el cual ha querido subrayar que la reforma, en cuanto ley, está promulgada y exige observancia, pues obedece a la Ley Suprema de la Iglesia, que es la salvación de las almas. 
al pie del mismo en el diario L'Osservatore Romano ${ }^{8}$; distintos organismos de la Santa Sede, vinculados con las causas matrimoniales, entregaron otras herramientas para facilitar la implementación de la reforma?

Ahora bien, antes de entrar en los cambios presentados por el Motu Proprio, es necesario señalar, en primer lugar, la decisión del Romano Pontífice de mantener las causas de nulidad matrimonial en el ámbito de la potestad judicial de la Iglesia; si bien algunos Padres Sinodales postulaban trasladar estas causas al ámbito de la potestad administrativa, el Papa mantuvo lo que ya había sido uniformemente sostenido por sus predecesores. En este punto resaltamos, entonces, la continuidad del magisterio pontificio. El Romano Pontífice aclara, en las consideraciones preliminares, que lo ha decidido así "no porque lo imponga la naturaleza de las cosas, sino porque lo exige la necesidad de tutelar en el grado máximo la verdad del sagrado vínculo"10.

El derecho canónico como tal, y en consecuencia el derecho procesal que forma parte del mismo, entra con sus motivos inspiradores en el plano de la búsqueda y entrega de la salvación; por ello es que todo él se inserta en la acción salvífica, por medio de la cual la Iglesia continúa la obra de la Redención. Concebido como instrumento para la defensa de los derechos, la eficacia del proceso judicial se medirá en relación a la protección de los derechos y deberes del fiel, dirigidos a la salvación eterna. De este modo, "es el proceso judicial el instrumento que mejor garantiza la defensa de los derechos y la búsqueda de la verdad objetiva acerca de la validez o invalidez del matrimonio" ${ }^{11}$. Cada una de las etapas que conforman el proceso, y las formalidades que el mismo reviste, presenta mejores condiciones de seguridad jurídica y protección de los derechos de los fieles, entre ellos el derecho de defensa.

Las distintas voces que se alzaron a favor de la vía administrativa para las causas matrimoniales, invocaban, en general, razones pastorales, fundadas en la celeridad y flexibilidad de que gozaría el procedimiento administrativo, más que en argumentos jurídicos que sostuvieran la preferencia por esa vía ${ }^{12}$. Aquí adherimos a la opinión del profesor Carlos

\footnotetext{
8 Explica el Decano que el propósito fue subrayar que las reformas ya promulgadas están ahora en vigor y deben ser seguidas y obedecidas, y que tratándose de una ley de gran importancia, es comprensible cierta resistencia, por ello el Papa Francisco deseaba enfatizar que la reforma promulgada exige cumplimiento, tal como en su momento lo hizo Juan Pablo II al promulgar el Código de Derecho Canónico de 1983. Véase francisco (2015 c) que incluye el comentario de Monseñor Pio Vito Pinto.

9 EL Tribunal Apostólico de la Rota Romana publicó un subsidio aplicativo del Motu proprio, dirigido a los operadores judiciales, que estructurado en dos capítulos, entrega distintas orientaciones para la aplicación de las nuevas normas, las que son presentadas como preguntas y respuestas, y con un breve resumen al final de cada tema, evidenciando la finalidad didáctica del Subsidio. El Pontificio Consejo para los Textos Legislativos, en su página web (http://www.delegumtextibus.va/content/testilegislativi/it/risposte-particolari/procedureper-la-dichiarazione-della-nullita-matrimoniale.html) permite acceder a las respuestas que ha ido entregando, conforme fue recibiendo consultas sobre el Motu proprio, pues estas respuestas -que en términos del canon 16 no constituyen interpretaciones auténticas- pueden contribuir a la correcta interpretación y aplicación de las nuevas normas. Asimismo, el Tribunal Apostólico de la Rota Romana ofreció un Curso de formación para los Obispos sobre el nuevo proceso matrimonial, en noviembre de 2016 y otro dirigido a los Párrocos, en febrero de 2017, ambos en Roma.

10 Proemio.

11 LÓPEz (2016) p. 55.

12 Sínodo de los obispos, III Asamblea General Extraordinaria (2014 b). La Relatio Synodi, en el n. 48, lo expone del siguiente modo: “Un gran número de los Padres subrayó la necesidad de hacer más accesibles y
} 
Morán Bustos, actual Decano del Tribunal de la Rota de la Nunciatura Apostólica en España, cuando en referencia a la Instrucción Dignitas Connubii señalaba: "a mi juicio, la decidida opción por la vía judicial para la resolución de las causas de nulidad no es de modo alguno incompatible -todo lo contrario- con la articulación, en su caso, de un proceso judicial más amplio, en el que se eliminen las formalidades innecesarias (en ese sentido han ido las sucesivas reformas legales del proceso) y, sobre todo, con un esfuerzo decidido, por parte de todos los responsables, por mejorar la administración de justicia en la Iglesia, mediante la dedicación de los medios materiales y humanos necesarios, la preocupación por la formación de los miembros de los tribunales"13.

En este mismo sentido, la instrucción Dignitas Connubii señala en el art. 5 que las causas de nulidad de matrimonio solo pueden ser resueltas por sentencia del tribunal competente, a la que equivale también el decreto ratificatorio del art. 265; la excepción está prevista en el mismo art. 5, para aquellos casos en los cuales resultaba evidente la nulidad, en los cuales la Signatura Apostólica tiene la facultad de decidir por decreto, y por la vía administrativa, la nulidad del matrimonio en aquellas causas que no exijan una especial investigación, sin que podamos dejar se resaltar el carácter excepcional de esta disposición y su fundamento en la equidad canónica, y que, además, la praxis de dicho Tribunal ha incorporado como requisito, que la causa no pudiera ser tratada por la vía judicial debido a, por ejemplo, la inexistencia de un tribunal local competente. Por otra parte, si el caso exigiera una investigación más acuciosa, debe remitirse la causa al tribunal competente ${ }^{14}$.

De este modo, el Papa Francisco viene a mantener la constante praxis eclesial respecto a la conveniencia de la vía judicial para la tramitación de la declaración de nulidad del matrimonio.

\section{LOS OBJETIVOS DE LA REFORMA Y LAS NOVEDADES INTRODUCIDAS PARA ALCANZARLOS}

Superadas las primeras reacciones al tiempo de darse a conocer el Motu proprio, y especialmente en los tres meses de vacancia que instauró el Romano Pontífice para su entrada en vigencia, corresponde ahora detenernos en las principales novedades introducidas por la reforma, enfocando el análisis en el ámbito de las causas matrimoniales, aun cuando las nuevas normas plantean grandes desafíos también en el camino previo al proceso judicial,

ágiles, posiblemente totalmente gratuitos, los procedimientos para el reconocimiento de los casos de nulidad. Entre las propuestas se indicaron: dejar atrás la necesidad de la doble sentencia conforme; la posibilidad de determinar una vía administrativa bajo la responsabilidad del Obispo diocesano; un juicio sumario a poner en marcha en los casos de nulidad notoria. Sin embargo, algunos Padres se manifiestan contrarios a estas propuestas porque no garantizarían un juicio fiable. Cabe recalcar que en todos estos casos se trata de comprobación de la verdad acerca de la validez del vínculo. Según otras propuestas, habría que considerar la posibilidad de dar relevancia al rol de la fe de los prometidos en orden a la validez del sacramento del matrimonio, teniendo presente que entre bautizados todos los matrimonios válidos son sacramento".

13 MorÁn (2007) p. 44.

14 BurKe (1992) pp. 93-105 donde expone sobre este procedimiento administrativo en sede de la Signatura Apostólica. 
y que involucran decisiones de gobierno del Obispo en cuanto a la organización diocesana para el ejercicio de la potestad judicial, y también con relación a la pastoral familiar, en la cual se inserta la labor de los tribunales judiciales. Si concentramos nuestra atención en el ámbito procesal, propiamente tal, una forma de abordar las modificaciones que ha experimentado el proceso es vincularlas a cada uno de los objetivos que se ha perseguido con tan importante reforma: accesibilidad, celeridad y gratuidad de los procesos.

\section{LAS MODIFICACIONES QUE CONTRIBUYEN A HACER LOS PROCESOS MÁS ACCESIBLES}

En primer lugar, a efectos de hacer los procesos más accesibles, y conforme el principio de proximidad entre el juez y los fieles, se han flexibilizado los títulos de competencia de los tribunales, permitiendo que las causas de nulidad sean iniciadas en el tribunal del lugar donde se celebró el matrimonio, en el del domicilio o cuasidomicilio de la parte actora, o bien en el de la parte convenida, y también en el lugar donde ha de recogerse la mayor cantidad de las pruebas, eliminando los requisitos que antes contemplaba el canon 1673, para poder hacer efectiva la competencia de alguno de esos tribunales ${ }^{15}$. La reforma propone, también, una etapa previa al inicio del proceso judicial, a la que denomina etapa prejudicial o pastoral, y que estará a cargo de estructuras diocesanas o parroquiales, donde agentes pastorales especializados tendrán la tarea de acoger a los fieles, discernir sobre su situación particular, y si es el caso, acompañarlos hacia el paso siguiente en el tribunal eclesiástico ${ }^{16}$. La expresión investigación prejudicial o pastoral, que utiliza el documento, busca mostrar la cercanía que debe existir entre esa primera atención pastoral y el camino a seguir hacia la presentación de una causa para la declaración de nulidad del matrimonio ${ }^{17}$, "de este modo ambos ámbitos no aparecen como inconexos, desprovistos de toda comunicación, como si trataran asuntos totalmente diferenciados, sino más bien como parte de una solo acción pastoral de la Iglesia, bajo la responsabilidad del Obispo, desarrollada en el ámbito de una pastoral familiar diocesana unitaria" ${ }^{18}$.

El proceso judicial para las causas matrimoniales debe convertirse, entonces, en "un instrumento jurídico eficaz, capaz de reconducir un planteamiento pastoral inicial" 19 , que parte en las estructuras eclesiales generadas para ello, y donde se hayan revelado antecedentes de una posible invalidez matrimonial. Para esto, la reforma debe ir acompañada de cambios profundos en la información y formación de los fieles sobre la nulidad matrimonial ${ }^{20}$.

\footnotetext{
15 El canon 1673 contemplaba que para iniciar la causa en el Tribunal del domicilio de la parte actora era necesario solicitar antes autorización del Vicario Judicial del domicilio de la convenida, habiendo oído previamente a esta, y siempre que ambas partes residieran en el territorio de la misma Conferencia Episcopal; si se acudía al Tribunal del lugar donde se recogería la mayor parte de las pruebas, también era necesaria la autorización del Vicario Judicial del domicilio de la parte convenida, habiendo oído previamente a esta, por si tuviera alguna objeción.

16 Reglas de procedimiento, art. 2; Francisco (2016 b) n. 244.

17 Bunge (2015) p. 7.

18 LÓPEZ (2016) p. 59.

19 Nieva García (2015) p. 90.

20 Sínodo de los obispos, III Asamblea General Extraordinaria (2014 a), n. 102 del Instrumentum laboris.
} 
Sobre ese punto, tanto en la Relatio Synodi como en el Discurso del Papa Francisco a la Rota Romana del año 2015, se menciona que "la preparación de suficientes agentes, clérigos y laicos, con dedicación prioritaria, exige resaltar la responsabilidad del Obispo diocesano, quien en su diócesis podría encargar a consultores debidamente preparados que aconsejaran gratuitamente a las partes acerca de la validez de su matrimonio" ${ }^{21}$, y así favorecer un acceso real de todos los fieles a la justicia de la Iglesia, en consonancia con lo establecido ya por el Código de Derecho Canónico y la Instrucción Dignitas Connubi2 ${ }^{22}$.

En ese escenario, enfrentamos el llamado que hace el Motu proprio para que, en la medida en que ello sea posible, cada diócesis inicie un camino hacia la constitución de su propio tribunal, si no lo tuviere, o bien a elegir de modo estable otro tribunal, diocesano o interdiocesano ${ }^{23}$, cercano a sus fieles, para facilitar el acceso a los mismos. También se llama a evaluar la conveniencia de restaurar la apelación a la Sede del Metropolitano, de modo que esta recupere su función de tribunal de apelación para los tribunales diocesanos, "ya que este oficio de cabeza de la provincia eclesiástica, estable en los siglos, es un signo distintivo de la sinodalidad de la Iglesia" ${ }^{24}$. En todo caso, no debemos olvidar que se pide a las Conferencias episcopales que "respeten absolutamente el derecho del Obispo diocesano de organizar la potestad judicial en la propia Iglesia particular"; brindando a cada Obispo "el estímulo y conjuntamente la ayuda para poner en práctica la reforma del proceso matrimonial" 25 .

\section{Celeridad PROCESAl EN las CAUSAS JUdiciales}

Ahora bien, con relación al objetivo de agilizar y simplificar los procesos judiciales, los principales cambios presentados por el Motu proprio orientados al mismo son la eliminación del requisito de doble sentencia conforme, el rechazo de la apelación manifiestamente dilatoria, y el proceso más breve ante el Obispo diocesano, siendo este último el que ha generado mayor atención en la doctrina ${ }^{26}$.

Al eliminar el requisito de una doble decisión conforme a favor de la nulidad, toda sentencia que declara por primera vez -en primera o ulterior instancia- la nulidad del matrimonio y que no es impugnada en los plazos establecidos, se hace ejecutiva, lo que "supone la vuelta al régimen común que rige para todos los procesos canónicos, según el cual una sola sentencia que ninguna de las partes - ni los cónyuges ni el defensor del vínculo- apele adquirirá firmeza, pudiendo ser ejecutada" ${ }^{27}$. No obstante, permanece íntegro el derecho de las partes y el defensor del vínculo, de interponer querella de nulidad o apelación, pues ello está directamente vinculado al ejercicio del derecho de defensa, y conforme los cánones res-

\footnotetext{
21 Sínodo de los obispos, ili Asamblea General Extraordinaria (2014 b), n. 49 de la Relatio Synodi; FranCISCO (2015 a).

22 Canon 1490 y art. 113, respectivamente.

23 Nuevo canon $1673,2$.

24 Proemio V.

5 Proemio VI.

26 Comentan en extenso este aspecto de la reforma, entre otros: Heredia (2016), Bianchi (2016), Del Pozo (2016), Sabbarese y Santoro (2016).

27 Peña García (2016) p. 55.
} 
pectivos a ambos institutos procesales, que no han sido modificados ${ }^{28}$. En este punto, otra particularidad del Motu proprio es que, si bien los nuevos cánones se aplican a toda causa matrimonial iniciada a partir del 8 de diciembre de 2015, la eliminación de este requisito rige para toda sentencia publicada - notificada- con posterioridad a esa fecha, independientemente de la fecha de inicio de la causa.

Por otra parte, íntimamente vinculado con el derecho de impugnar la sentencia, se encuentra la disposición del canon 1680, que permite al tribunal de apelación confirmar, a través de un decreto, la sentencia de primera instancia impugnada por medio de un recurso de apelación, si dicho tribunal considera la apelación manifiestamente dilatoria ${ }^{29}$. En efecto, "esto puede suceder en caso de apelación instrumental, para perjudicar a la otra parte; a menudo la parte recurrente no católica ya ha vuelto a casarse civilmente" ${ }^{30}$. Es necesario resaltar la excepcionalidad de este instituto, dado que el ejercicio del derecho a impugnar una sentencia que se considera injusta, está íntimamente ligado al ejercicio del derecho de defensa, que podría verse seriamente lesionado. Por otra parte, no se puede negar la dificultad de determinar cuándo una apelación puede considerarse meramente dilatoria, pues no podría referirse a la difícil tarea de valorar las intenciones de la parte recurrente, que, por lo demás, solo sería posible ante la presencia de hechos precisos y una conducta procesal en un todo coherente con la intención meramente dilatoria que se pretende adjudicar a la apelación. Más bien compartimos el criterio de que sería la evidente falta de argumentos del recurso, lo que permitiría al tribunal de segunda instancia confirmar por decreto la sentencia recurrida ${ }^{31}$.

Otro aspecto relacionado con la celeridad que se quiere obtener en la tramitación de las causas matrimoniales, y que representa, por otra parte, una de las grandes novedades de la reforma, es la regulación de un proceso más breve, ante el Obispo diocesano. En efecto, se presentan tres tipos de procesos para las causas matrimoniales, dos de los cuales ya existían en la legislación anterior al Motu proprio -el proceso ordinario y el proceso documental-, y el processus brevior, introducido por las nuevas normas.

Este último ha dado lugar a no pocos interrogantes, a los cuales la doctrina fue dando respuesta, a partir del estudio de las normas relativas al mismo y la propia praxis judicial de aquellos procesos ya iniciados bajo esta modalidad. Tengamos presente que, en todo caso, para una adecuada interpretación de las normas que lo regulan, y en vistas a su correcta aplicación, este proceso breve debe abordarse desde la perspectiva que otorga toda la normativa procesal del Código de Derecho Canónico, los principios que inspiran el proceso judicial en general, y los principios propios del sistema procesal canónico.

\footnotetext{
28 Nuevo canon 1680 , 1, que reenvía a su vez a los cánones 1619-1640. También, como signo reforzado del vínculo entre la Sede de Pedro y las Iglesias particulares, se mantiene el derecho a apelar a la Rota Romana.

29 Llobel (2015) p. 35. A propósito de la inadmisibilidad y falta de fundamento del recurso de apelación, el autor señala que la doctrina ha visto cierta semejanza entre la prosecución de la apelación y la demanda en primera instancia, en lo que atañe a la necesidad de un mínimo de bonus fumus iuris.

30 Bunge (2015 a). Así lo señaló el Prelado Auditor de la Rota Romana y Secretario de la Comisión Especial para la Reforma del Proceso Matrimonial Canónico, Pbro. Alejandro Bunge, en la conferencia de prensa de presentación del Motu proprio, el 8 de septiembre en la Oficina de Prensa de la Santa Sede.

31 Peña García (2016 b).
} 
En primer lugar, se ha visto necesario insistir en que los tres requisitos que contempla el canon 1683 para la admisibilidad de este tipo de proceso deben darse conjuntamente. En efecto, la mencionada norma exige que la petición haya sido propuesta por ambos cónyuges, o por uno de ellos con el consentimiento del otro, además, deben existir circunstancias que hagan manifiesta la nulidad del matrimonio, y, finalmente, esas circunstancias que sostienen con argumentos evidentes la nulidad, deben probarse fácilmente, en el sentido de no requerir una investigación o una instrucción más precisa. Con relación a la exigencia de nulidad manifiesta y evidente -conceptos que pueden resultar de difícil determinación- será necesario, por un lado, distinguirlo de la certeza moral que se exige al juez para declarar la nulidad del matrimonio, y por otro, señalar la importancia de la tarea a desarrollar en la investigación prejudicial o pastoral, la que podría revelar aquellas circunstancias que permitan calificar la nulidad como manifiesta, así como identificar los testimonios o documentos que pudieran sostenerla de tal modo que no hicieran necesaria una instrucción más precisa ${ }^{32}$.

El Romano Pontífice ha señalado expresamente que este juicio abreviado podría poner en peligro el principio de la indisolubilidad del matrimonio y por ello ha establecido que "en tal proceso sea constituido juez el mismo Obispo, que en virtud de su oficio pastoral es con Pedro el mayor garante de la unidad católica en la fe y la disciplina"33. Precisamente, "por tratarse de un proceso breve, donde a nadie escapan los riesgos que pueden presentarse en términos de la protección de la indisolubilidad del matrimonio, será el defensor del vínculo quien verá su oficio potenciado, asumiendo un rol capital”34.

El Motu proprio señala también las circunstancias de hecho cuya invocación permitiría acceder al proceso más breve ${ }^{35}$. Si bien resulta claro que la enumeración es a modo de ejemplo y no taxativa, se mencionan supuestos fácticos de muy distinta naturaleza, y que afectan de diversas formas el consentimiento matrimonial. El Subsidio Aplicativo elaborado por el Tribunal de la Rota Romana, como instrumento que contribuya a la correcta interpretación y aplicación de la reforma, enfatiza que estas circunstancias de hecho no son nuevos capítulos de nulidad, sino más bien, situaciones que la jurisprudencia ha ido marcando como síntomas evidentes de invalidez del consentimiento nupcial ${ }^{36}$. El mismo documento, se detiene brevemente en cada uno de dichos supuestos fácticos, entre los cuales se incluye la falta de fe en alguno o ambos contrayentes, que pudiera derivar en simulación del consentimiento o error que determine la voluntad, tema ya abordado anteriormente por Benedicto XVI en su Discurso a la Rota Romana del 26 de enero de $2013^{37}$, por el Papa

\footnotetext{
32 Para un detallado comentario sobre los requisitos del proceso más breve ante el Obispo diocesano, los interrogantes que abre el análisis de los mismos, y algunas respuestas entregadas ya por la doctrina, véase BIANCHI (2016).

33 Proemio IV.

34 LÓPEz (2016) p. 58.

35 Reglas de procedimiento, art. 14, 1.

36 Tribunal Apostólico de la Rota Romana (2016), Subsidio Aplicativo, II, 3.1, b).

37 Benedicto xvi (2013).
} 
Francisco, en sus Discurso a la Rota Romana de los años 2015 y $2016^{38}$ y ha sido objeto de análisis y comentarios por parte de la doctrina en el último tiempo ${ }^{39}$.

La constitución del juez único clérigo en primera instancia y la posibilidad de que dos laicos integren un tribunal colegial, son otras de las medidas con las cuales el Motu proprio pretende agilizar los procesos.

\section{GRATUidaD}

Ya en su Discurso a la Rota Romana del año 2015, el Papa Francisco se había expresado en estos términos sobre la gratuidad de los procesos: "Los sacramentos son gratuitos. Los sacramentos nos dan la gracia. Y un proceso matrimonial tiene que ver con el sacramento del matrimonio. ¡Cómo quisiera que todos los procesos fueran gratuitos!”40. Por tanto, no puede llamar la atención que en esta importante reforma sobre los procesos matrimoniales haya introducido también el tema de la gratuidad, Sin embargo, resulta también evidente que esta no podría imponerse como una exigencia a ser cumplida de forma inmediata por todos los tribunales, sino como un objetivo al que habrá que ir avanzando gradualmente. En ese sentido, el Legislador llama a que "en cuanto sea posible, y salvada la justa y digna retribución de los operadores de los tribunales, se asegure la gratuidad de los procesos" ${ }^{\prime \prime}$, señalando a las Conferencias episcopales como las encargadas de cuidar que ello sea así.

En efecto, el funcionamiento del tribunal, su infraestructura, el personal especializado y capacitado, implica un costo económico que ha de ser asumido. Hasta el momento, los tribunales han adoptado variados mecanismos para encausar todo lo relacionado con las costas judiciales, en cuanto al modo de cuantificar el costo asociado a un proceso matrimonial, quién asume ese costo, en qué circunstancias conceder el beneficio de gratuidad, entre otros puntos a definir.

La gratuidad propuesta en la reforma, contribuirá también a uniformar, en gran medida, todo lo relacionado con el tema de las costas judiciales, al menos respecto de los fieles que inician un proceso de nulidad matrimonial. Otro tema será la manera en que cada Obispo -en su diócesis y para su tribunal- resuelva con relación a la forma de asumir ese costo que efectivamente conlleva el funcionamiento del tribunal y el diligenciamiento de cada proceso matrimonial. Las nuevas normas buscan que no sean las partes quienes carguen con ello, ya que podría representar un obstáculo para acudir al tribunal en busca de una respuesta sobre la posible nulidad del matrimonio.

Implementar la gratuidad no solo requiere de un plan gradual que permita alcanzar el objetivo, sino, en especial, un cambio en la forma de comprender el verdadero

\footnotetext{
38 Francisco (2015 a) y Francisco (2016 a).

39 Sobre este particular han comentado Rincón-Pérez (2012), GAS Aixendri (2013), Ortiz (2015) y GAS AiXendri (2015), entre otros. El texto final del n. 48 de la Relatio synodi señala, también, en este sentido: "habría que considerar la posibilidad de dar relevancia al rol de la fe de los prometidos en orden a la validez del sacramento del matrimonio, teniendo presente que entre bautizados todos los matrimonios válidos son Sacramento".

40 Francisco (2015 a).

41 Proemio VI.
} 
sentido de estos procesos y de la administración de justicia en la Iglesia. Este objetivo está directamente relacionado, también, con la intención de hacer los procesos más accesibles a los fieles, ya que elimina el factor económico como un eventual problema a considerar, antes de tomar la decisión de iniciar una causa matrimonial. En este mismo sentido ya se señalaba la conveniencia de que el Obispo, en su diócesis, pudiera encargar a consultores debidamente preparados que aconsejaran gratuitamente a las partes acerca de la validez de su matrimonio ${ }^{42}$.

\section{CONCLUSIÓN}

En este tiempo inicial de vigencia de las modificaciones introducidas por el Motu proprio Mitis Iudex Dominus Iesus, la doctrina ha encontrado un campo fértil para reflexionar sobre los desafíos que las mismas proponen y los interrogantes que se abren con cada una de las novedades que presentan, entregando sus conclusiones en distintos foros y publicaciones especializadas, que este ensayo ha buscado señalar. Asimismo, aunando esfuerzos con la autoridad eclesiástica -universal y particular- continuarán contribuyendo a la mejor interpretación y aplicación de las nuevas normas.

Estamos en condiciones de afirmar que nos encontramos en presencia de una de las reformas más importantes que ha tenido lugar en el ámbito del derecho procesal canónico, y ello por varios motivos. En efecto, en materia de potestad de gobierno, pone de relieve el papel del Obispo y su misión de juzgar en la Iglesia ${ }^{43}$, pues es llamado a disponerse a ejercerla personalmente, en el ámbito de las causas matrimoniales, y específicamente en los procesos más breves ${ }^{44}$. Por otra parte, y desde una perspectiva pastoral, resalta esta dimensión de los tribunales eclesiásticos, insertos así en toda la pastoral familiar de la Iglesia particular, bajo la dirección y responsabilidad del Obispo. En consonancia con esa forma de entender la labor de los tribunales, se establece una etapa previa al inicio del proceso judicial, propiamente tal, que consiste en una acogida pastoral de las personas que se encuentran en situación de quiebre matrimonial, separación y divorcio ${ }^{45}$, brindando también atención jurídico canónica especializada, a cargo de agentes debidamente formados a tal efecto.

En el ámbito estrictamente procesal, la reforma exige hacer una adecuación en el desarrollo de los procesos -ordinario, documental y más breve- de modo que se incorporen las modificaciones introducidas en cada una de las etapas de los mismos, desde su inicio y hasta su fin, una vez que la sentencia definitiva deviene ejecutiva. Para ello, se debe contar con un equipo de personas suficientemente formadas en este ámbito.

\footnotetext{
42 Sínodo de los obispos, III Asamblea General Extraordinaria (2014), n. 49 de la Relatio Synodi.

43 Peña García (2015) pp. 629-631.

44 Bunge (2015 b) p. 5. En ese sentido lo expuso el Prelado Auditor de la Rota Romana y Secretario de la Comisión Especial para la Reforma del Proceso Matrimonial Canónico, Pbro. Alejandro Bunge, ante la Asamblea Plenaria de la Conferencia Episcopal Argentina, los días 9 y 10 de noviembre de 2015.

45 Sínodo de Obispos, XiV Asamblea General Ordinaria (2015) que en su n. 79 señala: "De ahí la necesidad de una pastoral de la conversión y la reconciliación a través de los centros de escucha y mediación especializados que habría que establecer en las diócesis".
} 
Una vez más, entonces, nos encontramos frente a la importancia de la formación en una materia tan específica como la que aborda la reforma. Un punto de reflexión que aquí se presenta, es cómo instrumentar adecuadamente esa formación. Sin duda, los estudios en facultades de derecho canónico, tanto por parte de sacerdotes, religiosos y laicos, que luego se incorporen a las distintas áreas de trabajo de la diócesis -relacionadas con el derecho matrimonial sustantivo y procesal- será la vía de formación por excelencia. Sin embargo, con conciencia clara y cierta de que ello no siempre será posible, no cabe duda que los mejores resultados en materia de formación emergerán del trabajo -conjunto o al menos coordinado- de asociaciones de canonistas, tribunales eclesiásticos, áreas de pastoral familiar de las diócesis, y también de institutos, facultades y universidades, dispuestos a colaborar en la tarea de diseñar e impartir programas de formación estables, para todos los agentes que son llamados a trabajar en los distintos ámbitos vinculados a la reforma -investigación pastoral, tribunales- facilitando con ello el cumplimiento de los objetivos propuestos por la misma.

\section{BIBLIOGRAFÍA CITADA}

Benedicto xVI (2013): "Discurso del Santo Padre Benedicto XVI en la inauguración del año judicial del Tribunal de la Rota Romana”. Disponible en: https://www.vatican.va/ content/benedict-xvi/es/speeches/2013/january/documents/hf_ben-xvi_spe_20130126_ rota-romana.html. Fecha de consulta: 5 de febrero de 2017.

Bianchi, Paolo (2016): "Criteri per l'accettazione del "processus brevior", en FranCESCHI, Héctor y Ortiz, Miguel Ángel (edit.), VI Corso di aggiornamento in diritto matrimoniale e processuale canonico. Roma 19-23 settembre 2016 (Ciudad del Vaticano, EDUSC, en prensa).

Bunge, Alejandro (2015 a): "Presentación de los Motu Proprio del Papa sobre la reforma del proceso de nulidad matrimonial". Disponible en: http://www.news.va/es/news/ presentacion-de-los-motu-proprio-del-santo-padre-2. Fecha de consulta 16 enero 2017.

Bunge, Alejandro (2015 b): "Presentación del nuevo proceso matrimonial". Disponible en: http://www.awbunge.com.ar/Nuevo-Proceso-Matrimonial.pdf. Fecha de consulta: 5 de febrero de 2017.

BURKE, Raymond (1992): "La procedura administrativa per la dichiarazione di nullità del matrimonio", Annali di dottrina e giurisprudenza canonica 16. Studi Giuridici 27: pp. 93-105.

Del Pozo, Massimo (2016): Il processo matrimoniale più breve davanti al vescovo (Roma, Edizioni Santa Croce).

Francisco (2015 a): "Discurso del Santo Padre Francisco con ocasión de la inauguración del año judicial del Tribunal de la Rota Romana”. Disponible en: https://www.vatican.

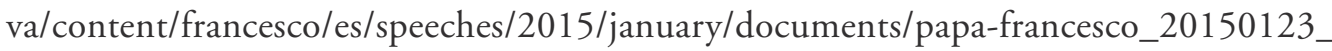
tribunale-rota-romana.html. Fecha de consulta: 5 de febrero de 2017.

Francisco (2015 b): "Litterae Apostolicae Motu Proprio datae Mitis Iudex Dominus Iesus quibus canones Codicis Iuris Canonici de causis ad matrimonii nullitatem declarandam reformantur", Acta Apostolicae Sedis 107: pp. 958-970. 
Francisco (2015 c): "Litterae Apostolicae Motu Proprio datae Mitis et Misericors Iesus quibus canones Codicis Canonum Ecclesiarum Orientalium de Causis ad Matrimonii nullitatem declarandam reformantur ”, Acta Apostolicae Sedis 107: pp. 946-957.

Francisco (2015 d): "Rescritto 'ex audientia' sulla riforma del processo matrimoniale introdotta dai due motu proprio pontifici del 15 agosto 2015". Disponible en: http:// www.osservatoreromano.va/it/news/prossimita-della-chiesa. Fecha de consulta: 4 de febrero de 2017.

Francisco (2016 a): "Discurso del Santo Padre Francisco con motivo de la inauguración del año judicial del Tribunal de la Rota Romana”. Disponible en: https://w2.vatican.va/ content/francesco/es/speeches/2016/january/documents/papa-francesco_20160122_anno-giudiziario-rota-romana.html. Fecha de consulta: 5 de febrero de 2016.

Francisco (2016 b): Exhortación Apostólica Postsinodal Amoris Laetitia sobre el amor en la familia (Santiago, Ediciones UC).

Gas AiXendri, Montserrat (2013): "Fede e intenzione nel matrimonio sacramento", Ius Ecclesiae 25: pp. 519-533.

Gas Aixendri, Montserrat (2015): “È possibile un matrimonio valido senza fede?”, en Franceschi, Héctor y Ortiz, Miguel Ángel (edit.), Ius et Matrimonium. Temi di diritto matrimoniale e processuale canonico (Roma) pp. 143-162.

Heredia, Felipe (2016): "El proceso más breve ante el Obispo", Anuario de Derecho Canónico 5 Suplemento: pp. 97-122.

Juan Pablo II (1983): Código de Derecho Canónico (Ciudad Autónoma de Buenos Aires, Oficina del Libro de la Conferencia Episcopal Argentina, primera edición bilingüe).

Llobel, Joaquín (2015): "Alcune questioni comuni ai tre processi per la dichiarazione di nullità del matrimonio previsti dal M.P. 'Mitis Iudex'”, Ius Ecclesia, v. XXVIII No 1: pp. 13-38.

López, Valeria (2016): "Desafíos de las nuevas normas para los procesos matrimoniales", Anuario Canónico vol. II: pp. 51-63.

Morán Bustos, Carlos y Peña García, Carmen (2007): Nulidad de matrimonio y proceso canónico. Comentario adaptado a la Instrucción Dignitas Connubii (Madrid, Dykinson S.L., primera edición).

Nieva García, Joaquín Alberto (2015): Reforma del proceso canónico para la declaración de nulidad del matrimonio y pastoral de los fieles divorciados y vueltos a casar (Madrid, Ediciones Universidad San Dámaso).

Ortiz, Miguel Ángel (2015): "Fe y matrimonio", en Bosch, Jordi (edit), Cuestiones actuales de Derecho Canónico y Derecho Eclesiástico del Estado (Roma, Dykinson) pp. 283-288.

Peña García, Carmen (2015): "La reforma de los procesos canónicos de nulidad matrimonial: el Motu proprio 'Mitis Iudex Dominus Iesus', Estudios Eclesiásticos, vol. 90, N. 355: pp. 621-682.

Peña García, Carmen (2016 a): "Agilización de los procesos canónicos de nulidad matrimonial; de las propuestas presinodales al motu proprio Mitis Iudex Dominus Iesus y retos pendientes tras la reforma", Ius Canonicum, v. 56: pp. 41-64.

Peña García, Carmen (2016 b): "La apelación en las causas matrimoniales", en Franceschi, Héctor y Ortiz, Miguel Ángel (edit.), VI Corso di aggiornamento in diritto 
matrimoniale e processuale canonico. Roma 19-23 settembre 2016. (Ciudad del Vaticano, EDUSC, en prensa).

Pontificio Consejo para los Textos Legislativos (2005): Instrucción Dignitas Connubii (Ciudad del Vaticano, Librería Editrice Vaticana, primera edición).

SabBarese, Luigi y SAntoro, Raffaele (2016): Il processo matrimoniale più breve. Disciplina canonica e riflessi concordatari (Bologna, Edizione Dehoniane).

RinCÓN-PÉrez, Tomás (2012): "Fe para la celebración del matrimonio”, en OtAduY, Javier Viana, Antonio y Sedano, Joaquín (edit.), Diccionario General de Derecho Canónico, Vol. III (Navarra, Thomson Reuters Aranzadi, Cizur Menor) pp. 937-942.

Sínodo de los Obispos, III Asamblea General Extraordinaria (2013): "Los desafíos pastorales sobre la familia en el contexto de la Evangelización. Documento preparatorio". Disponible en: http://www.vatican.va/roman_curia/synod/documents/rc_synod_ doc_20131105_iii-assemblea-sinodo-vescovi_sp. html. Fecha de consulta: 4 de febrero de 2017.

Sínodo de los Obispos, III Asamblea General Extraordinaria (2014 a): "Los desafíos pastorales sobre la familia en el contexto de la Evangelización. Instrumentum Laboris". Disponible en: http://www.vatican.va/roman_curia/synod/documents/rc_synod_ doc_20140626_instrumentum-laboris-familia_sp. html. Fecha de consulta: 4 de febrero de 2017.

Sínodo de los Obispos, III Asamblea General Extraordinaria (2014 b): "Los desafíos pastorales sobre la familia en el contexto de la Evangelización. Relatio Synodi". Disponible en: http://www.vatican.va/roman_curia/synod/documents/rc_synod_ doc_20141018_relatio-synodi-familia_sp. html. Fecha de consulta: 4 de febrero de 2017.

Sínodo de los obispos, XIV Asamblea General Ordinaria (2015): "La vocación y la misión de la familia en la Iglesia y en el mundo contemporáneo. Relación final”. Disponible en: http://www.vatican.va/roman_curia/synod/documents/rc_synod_ doc_20151026_relazione-finale-xiv-assemblea_sp. html. Fecha de consulta: 2 de febrero de 2016.

Tribunal Apostólico de la Rota Romana (2016): "Subsidio aplicativo del Motu proprio Mitis Iudex Dominus Iesus". Disponible en: http://www.rotaromana.va/content/dam/ rotaromana/documenti/Sussidio/Subsidio\%20Aplicativo, \%20espa\%C3\%B1ol.pdf. Fecha de consulta: 17 de enero 2017. 